\title{
Fresh-frozen plasma use in a South African tertiary hospital
}

\author{
Adele Visser, Annelize Geldenhuys, Samantha du Preez, Annemarie van de Vyver
}

Despite available guidelines on indications for fresh-frozen plasma (FFP) transfusion, inappropriate use is increasing worldwide. We evaluated FFP administration to patients admitted to the Steve Biko Academic Hospital over 4 months, including indications for use and completeness of requisition forms. Transfusions were considered inappropriate for $39.5 \%$ of units administered. Of request forms submitted, only $22 \%$ had sufficient information for the blood transfusion services of the indication for transfusion. Transfusion with FFP is a medical intervention that carries risks and should be undertaken with care. Although this study was conducted in one centre, it is evident that clinicians' lack of knowledge of the indications for administration of FFP is widespread. Intervention is necessary to improve patient outcomes and reduce expenditure.

S Afr Med J 2012;102(6):366-367
Transfusion of blood and blood products is a potentially life-saving measure, but is not without risk. ${ }^{1}$ Fresh-frozen plasma (FFP) is produced from a single whole-blood donor unit, or through plasmapheresis. ${ }^{2}$ Despite the lack of cellular components in FFP, complications may follow transfusion. These include allergic reactions, transfusion-related acute lung injury (TRALI), haemolysis, fluid overload and infectious complications. ${ }^{3}$ Therefore, FFP transfusion should be restricted to cases where its clinical benefit has been established. ${ }^{1}$

Despite available guidelines on appropriate indications, ${ }^{2}$ there is increasing worldwide use of FFP transfusion ${ }^{4}$ with inappropriate indications, ${ }^{5}$ particularly in tertiary healthcare settings. ${ }^{4}$ We evaluated the utilisation of FFP and the prescription practices of attending clinicians in a South African tertiary hospital.

Division of Clinical Pathology, Department of Medical Microbiology, University of Pretoria, and National Health Laboratory Service (Tshwane Academic Division), Pretoria

Adele Visser, MB ChB, DTM\&H, PG (Dip) TM, MMed (Clin Path), FCPath (SA) (Clin Path)

Department of Haematology, University of Pretoria, and National Health Laboratory Service (Tshwane Academic Division), Pretoria

Annelize Geldenhuys, MB ChB, DA (SA), PG (Dip) TM

Samantha du Preez, MB ChB, PG (Dip) TM

Department of Internal Medicine, Kalafong Hospital, and University of Pretoria Annemarie van de Vyver, BSc, MB ChB, PG (Dip) TM

\section{Materials and methods}

All patients who received FFP transfusions from February to April 2010 at the Steve Biko Academic Hospital were included. All units were exclusively requested by doctors, and indications of transfusion and completeness of requisition forms were evaluated.

Appropriate indications were based on Guidelines of the South African National Blood Transfusion Service (SANBS). Absolute indications are: replacement of single-factor deficiencies when factor concentrate was not available, immediate reversal of warfarin effect, vitamin $\mathrm{K}$ deficiency associated bleeding, acute disseminated intravascular coagulation (DIC),

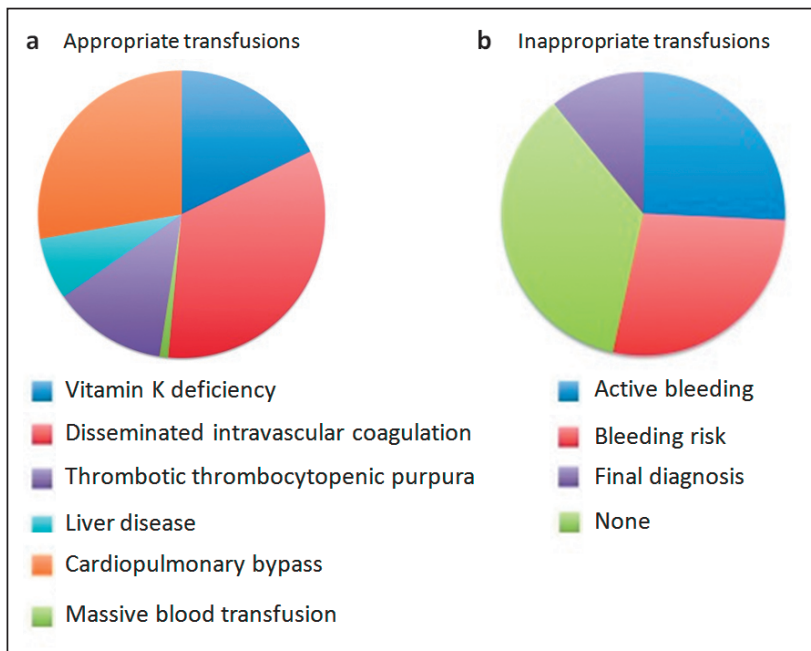

Fig. 1. Breakdown of indications stated on request forms for requisition and transfusion of FFP: $\boldsymbol{a}$-cases where transfusions were deemed appropriate, and $\boldsymbol{b}$ - cases where transfusions did not comply with SANBS guidelines. 
thrombotic thrombocytopenic purpura (TTP), inherited deficiencies in coagulation, and suxamethonium chloride apnoea. Conditional uses include liver disease, cardiopulmonary bypass surgery, and as part of a massive transfusion.

\section{Results}

In total, 416 requests were submitted for FFP, amounting to 1020 units transfused in 312 patients. Internal Medicine, General Surgery, Surgical ICU, and Obstetrics and Gynaecology were the departments that used the most FFP units. Of units transfused, 289 (39.5\%) were considered inappropriate. Of the more than $60 \%$ of appropriately transfused units, disseminated intravascular haemolysis and massive transfusions accounted for more than $60 \%$. Vitamin $\mathrm{K}$ deficiency (with or without warfarin effect) in the presence of active bleeding accounted for $20 \%$ of cases (Fig. 1). Most of the inappropriate transfusions were classified as the patient's final diagnosis stated on the request form, which had no bearing on the indication for transfusion. Despite evaluating the patients' laboratory records, the reasons warranting transfusion with FFP could not be determined. In more than $25 \%$ of cases, patients had features of bleeding, but FFP was administered without red-cell concentrate, and they did not fit the criteria for a massive transfusion. In the remainder, patients were either at risk of bleeding with no active bleeding at the time of ordering FFP and no subsequent laboratory features of bleeding (decrease in haemoglobin concentration or haematocrit), or no indication or diagnosis was supplied. Of note, most of the bleeding risks were due to platelet dysfunction (renal failure or idiopathic ITP), and administration of FFP would have had minimal impact. Most of these inappropriate cases were from the Departments of Obstetrics and Gynaecology and Internal Medicine. Of all request forms submitted, only $22 \%$ contained sufficient information for the blood transfusion services of the indication for transfusion.

\section{Discussion}

FFP is a frequently used blood-derived product, and worldwide inappropriate use has been noted. ${ }^{4}$ This has a significant impact on medical costs and patient morbidity and mortality. ${ }^{1}$ To identify areas for improved patient care and reduced resource expenditure, it is essential to determine local utilisation practices and adherence to guidelines. The auditing process is valuable in determining areas requiring improvement, and its use in transfusion medicine has been advocated. ${ }^{6}$ Evaluation of the requisition forms is a valuable indicator of appropriateness of FFP ordering. ${ }^{3}$ Therefore, we used both these parameters in our study to evaluate local utilisation practices of FFP.

Inappropriate FFP use should prompt interventions including the use of local guidelines in hospital training, ${ }^{3}$ continuing professional development programmes, ${ }^{3}$ discussing patients receiving blood or blood products on daily ward rounds, ${ }^{6}$ and the use of computerised monitoring programmes. Although these have been implemented with varying degrees of success, intervention is needed when considering global trends in FFP use.

In conclusion, transfusion with FFP is a medical intervention that carries a risk and should be undertaken with due care. Although this study was done in one centre, it is evident that clinicians lack knowledge of appropriate indications for the administration of FFP. Intervention is necessary to improve patient outcomes and reduce expenditure.

\section{References}

1. Kakkar N, Kaur R, Dhanoa J. Improvement in fresh frozen plasma transfusion practice: results of an outcome audits. Transfus Med 2004;14:231-234. [http://dx.doi.org/10.1111/j.0958-7578.2004.00505.x] 2. South African National Blood Transfusion Service. Bird A, Mpuntsha L, eds. Clinical Guidelines for the Use of Blood Products in South Africa. 4th ed. Johannesburg: SANBS, 2008

3. Ioro A, Basileo M, Marchesini E, et al. Audit of the clinical use of fresh-frozen plasma in Umbris a study design and results of the pilot phase. Blood Transfus 2008;6(4):211-219. [http://dx.dol org/10.2450/2008.0042-07]

4. Laird J, Soutar R. Effective transfusion audit can improve and later clinical practice: somethin that is often questioned. Transfus Med 2008;18:141-142. [http://dx.doi.org/10.1111/j.13653148.2008.00845.x]

5. Hui C, Williams I, Davis K. Clinical audit of the use of fresh-frozen plasma and platelets in a tertiary hospital and the impact of a new transfusion request form. Int Med 2005;35:283-288. [http://dx.doi

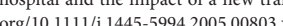

6. Toy P. The transfusion audit as an educational tool. Transfus Sci 1998:19(1):91-96. [http://dxdoi org/10.1016/S0955-3886(98)00013-9]

Accepted 13 February 2012 